Proceedings

\title{
Energetic Sustainability of Systems ${ }^{+}$
}

\author{
Attila Albini *, Edina Albininé Budavári $\mathbb{1}$ and Zoltán Rajnai \\ Doctoral School on Safety and Security Sciences, Obuda University, 1034 Budapest, Hungary; \\ budavari.edina@phd.uni-obuda.hu (E.A.B.); rajnai.zoltan@bgk.uni-obuda.hu (Z.R.) \\ * Correspondence: attila.albini@gmail.com \\ + Presented at the 14th International Conference on Interdisciplinarity in Engineering-INTER-ENG 2020, \\ Târgu Mureș, Romania, 8-9 October 2020.
}

Published: 25 December 2020

check for updates

\begin{abstract}
An important problem in our world is that humanity's energy consumption is constantly rising. Therefore, nowadays there is an increasing emphasis on the problem of reusability and efficient energy management. The present paper studies the energy sustainability of systems by developing a unique test model. Using this test model, the theoretical problems of closed systems are investigated. With a theoretical experiment, the temporal motion of rigid systems is monitored and the behavior of flexible systems is analyzed. Finally, the study of the energy interaction of the general system and its environment shows the basic condition for the system's overall sustainability.
\end{abstract}

Keywords: closed system; dual system; ideal system; energetic model; long-term sustainability

\section{Introduction}

An important problem in our world is that humanity's energy consumption is constantly rising. Therefore, nowadays there is an increasing emphasis on the problem of reusability and efficient energy management [1-3]. Among other things, increasing efficiency is one of the requirements for the existence of long-term sustainable systems. Due to energy hunger, the need for sustainability is emerging in all areas of life. Demand is emerging everywhere from the industry's new paradigmatic concept to the smart city concept [4-7]. From other aspects, the need for sustainability must be emphasized in the underlying legal regulation [8] and in education [9-11].

The long-term sustainability of systems can be examined by the energy balance of the system. The aim of the present study is to examine the energy relationship between the ideal system and its environment in theoretical experiments, and to use this to demonstrate the energy conditions for the long-term sustainability of systems. The result can help to understand the relationship between the flexibility, efficiency and sustainability of systems. Furthermore, the result can help to show the dependence of the energy requirement of sustainability.

There are several arguments in favor of the energy aspect. The analysis of the movement of systems over time differs depending on the structural changes [12-14]. Structurally static motion can be modeled with the loops of cybernetics. This modeling leads to a system of differential equations with a static structure [15-21]. The result of organic change is a system of equations with a variable structure that cannot be handled easily. The study of such system changes is more based on textual modeling of human-based systems' change management. Long-term sustainability requires structural change. The energetic modeling of this is problematic because of the above. The series of theoretical experiments seeks a solution to this problem.

\section{Methods}

The study is based on the results of energy balance modeling according to [3]. Said modeling showed the energy relationship of the system components and the whole system and grouped the 
energy issues. Theoretical experiments have analyzed the energy balance [1-3] of several types of system connections. As a first theoretical experiment, the problem of closed systems was investigated. Ideal dual relationships were modeled in the second series of theoretical experiments. In the third phase of the experiments, one of the actors in the dual relationship was replaced by the outside world. With this method, the operation of real systems can be deduced in several steps. It is also possible to formulate the energy conditions for long-term sustainability.

To achieve this:

1. one should create a system model to be used to investigate the problem;

2. the problem of closed systems should be investigated. Based on this, a conclusion can be drawn for singular cases;

3. a test model should be developed in which only two systems have an ideal relationship. This constitutes the general dual system testing model. It should examine the relationship between structurally different systems:

a. the dual relationship of rigid systems must be examined;

b. the dual relationship between fully flexible systems needs to be examined;

4. in the dual test model, one system must be replaced with the complement of the other system.

Thus, the two systems in the study are the same as the system and the world outside it. Generalization is the aim of this theoretical experimental step, from which conclusions can be drawn regarding the general sustainability requirements of systems.

\section{Results}

The structure of the model produced for the tests is the same as the general simplified model of the systems. In terms of energy balance, the behavior of the system can be characterized by the behavioral pattern of the general energy model. The mechanism of the interaction of the systems can be modeled with the model of cybernetic loops $[15,16,19]$. Theoretical experiments should be performed on the resulting system model.

Using the energy model of general systems, it can be shown that ideal closed systems are completely safe [22-25]. However, information on such systems cannot be obtained in reality, so their existence has not been proven. Thus, closed systems are only worth talking about at the level of a theoretical model. An examination of the pairwise interaction of the systems showed that rigid systems devour each other, while flexible systems are in balance with each other. Theoretical examination of the system and its environment has shown that the energetic condition for the long-term sustainability of the systems is that the stored energy of the system shows a continuous and unlimited increase. Summarizing the results:

- modeling of perfectly closed systems is only possible in theory, their existence cannot be proved,

- completely rigid systems engulf each other;

- perfectly flexible systems are balanced;

- the energy condition for sustainability is the continuous and unlimited growth of stored energy. This result is consistent with the experience that the energy of the long-life systems increases exponentially.

\section{Discussion}

The series of experiments is based on a modeling procedure not used so far. It uses the general energy and structural model of the systems simultaneously. The logical sequence of the series of theoretical experiments is also unique. The cases that resulted in anomalies are also examined during the experiments. For this reason, the sequence of experiments provides a way to answer the problem and get closer to real systems. 


\subsection{Model}

Since the aim is to study the energy conditions, the application of the operating model used in the energy balance modeling of the systems may be expedient. According to this, the energy entering the system is equal to the sum of the change in stored energy and the energy leaving the system. The relevant equation is:

$$
\mathrm{E}(\text { in })=\Delta \mathrm{E}(\text { store })+\mathrm{E}(\text { out }) \text {. }
$$

In performing theoretical experiments, the logical separation of each experiment is based on the structure of the systems. For this reason, it is worth using the structure of the information system simplified system model [12-14] to model the structures of the systems. According to this, systems can be easily structurally modeled by defining the system, its properties, and the designation of its interface. In this case, the energy exchange of the system is only possible through its interface.

Finally, to model the interaction of systems, it is worth borrowing the mechanism of action of the cybernetic loops used in control theory [15-19]. According to this, negative feedback control loops were used to control the system according to the chain of action within the system. Based on the evaluation of the output, an intervention was made at the input of the chain to achieve the desired effect. This model assumes that the system is continuously exposed to external disturbances. The general model of the study is shown in Figure 1.

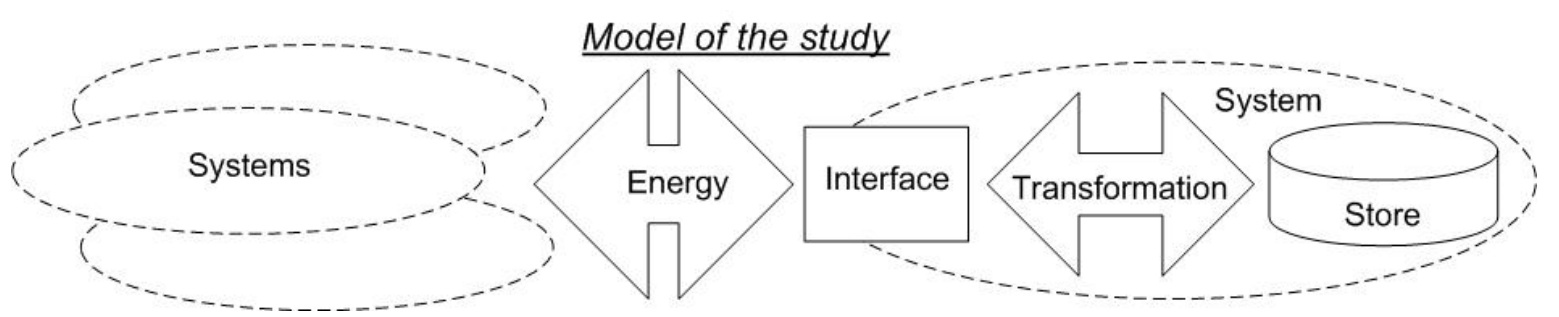

Figure 1. Model of the study. Based on [3].

\subsection{Closed Systems}

The interface of a perfectly closed system model is an empty set. This means that such systems are unsuitable for energy exchange. As a result, there is no exchange of information between the closed system and its environment. They know nothing about each other. Therefore, the discussion of closed systems is purely theoretical. In practice, such systems cannot be observed. A simplified structural model of closed systems is shown in Figure 2.

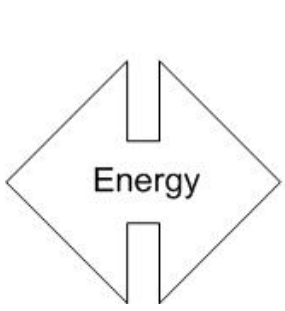

\section{Closed system model}

No interface
No energy flow
No information

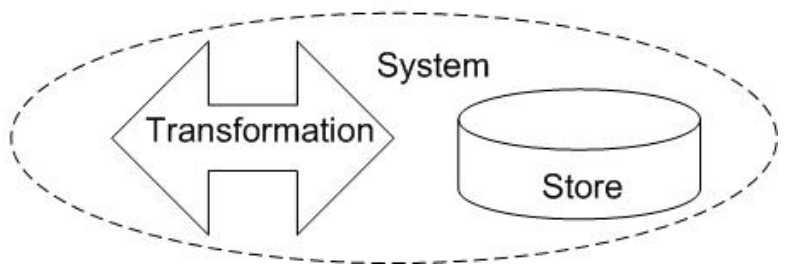

Figure 2. Simplified structural model of closed systems. Based on [3].

\subsection{Dual Systems}

At the beginning of the study of the interaction of systems, it is worth creating a general model. According to this model, there is no system in the imaginary world other than the two systems studied. The effect of one system is in interference with the other system and vice versa. Thus, the energy exchange also takes place only between the two systems. That is, systems only communicate energy to each other. The life of this dual system is determined by the variability of the energy transfer capacity 
and the structure of each system. The relevant equations are (2) and (3). The system identifiers $\left(E_{1}\right.$ and $\mathrm{E}_{2}$ ) are in the lower index.

$$
\begin{aligned}
& \left.\mathrm{E}_{2}(\text { out })=\mathrm{E}_{1}(\text { in })=\Delta \mathrm{E}_{1} \text { (store }\right)+\mathrm{E}_{1}(\text { out }), \\
& \left.\mathrm{E}_{1} \text { (out) }=\mathrm{E}_{2}(\text { in })=\Delta \mathrm{E}_{2} \text { (store }\right)+\mathrm{E}_{2}(\text { out }) .
\end{aligned}
$$

The model of the dual systems is shown in Figure 3.

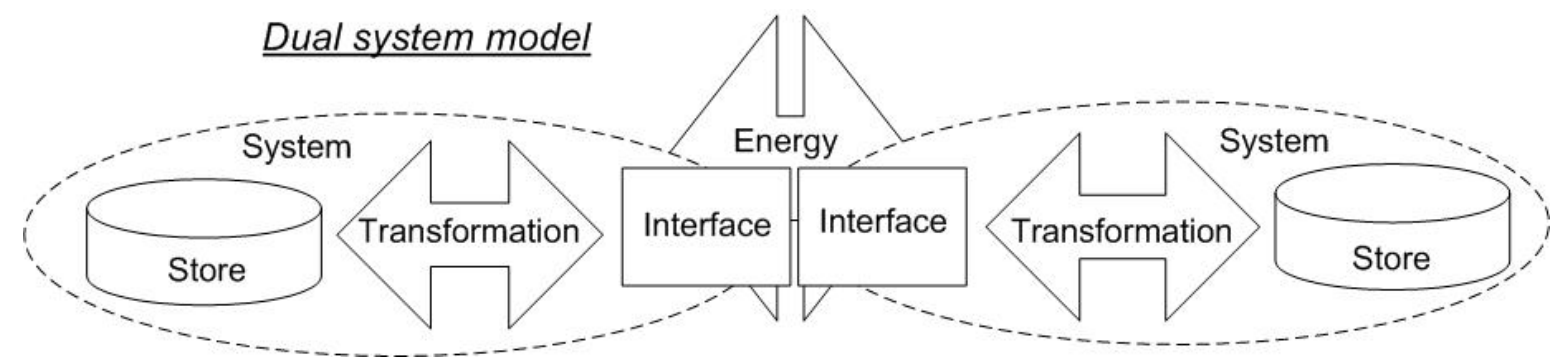

Figure 3. Model of the dual systems. Based on [3].

\subsection{Rigid Dual Systems}

Rigid systems are systems in which it is not possible to flexibly change the energy storage capacity of the system. As a result, it is not possible to quickly change the structure of the system. Almost all of the energy entering the system serves the operation of the system, which energy leaves the system after work. In the case of a dual examination of these systems, systems that are the same in terms of energy balance operate in balance with each other. This is based on Equations (2) and (3). The consequence is Equation (4). Due to the rigidity of the structures, the equilibrium condition is Equation (5).

$$
\begin{gathered}
\Delta \mathrm{E}_{1}(\text { store })+\Delta \mathrm{E}_{2}(\text { store })=0, \\
\Delta \mathrm{E}_{1}(\text { store })=\Delta \mathrm{E}_{2}(\text { store })=0
\end{gathered}
$$

This balance is not ideal. Although a small deviation causes the excess energy to be absorbed by the other system without damage, the difference between the systems involved in the study gradually increases. As a result, the higher energy system swallows up the lower energy system. In the event of a high degree of difference in systems, this effect is immediate and severe. So, it is characteristic of rigid systems that they seek to achieve singularity.

\subsection{Flexible Dual Systems}

Flexible structured systems are systems that are capable of rapid structural change. This is conditional on the possibility of storing a large part of the incoming energy. The energy demand for the operation of the system is much lower than the energy storage capacity. In the case of a dual examination of these systems, the identical systems are also in balance. Here, however, small differences are immediately offset because the ability of systems to change is rapid. The system can store the incoming excess energy without structural damage. The equilibrium condition is (6).

$$
\Delta \mathrm{E}_{1}(\text { store })+\Delta \mathrm{E}_{2}(\text { store })=\Delta \mathrm{E}_{1}(\text { out })=\Delta \mathrm{E}_{2}(\text { out })
$$

As a result, the energy balance of systems with different parameters and the amount of stored energy are balanced in the long run. So, flexible systems maintain a stable state of equilibrium with their environment. 


\subsection{Complementary Dual Systems}

During the complementary test, one of the dual systems must be replaced with the complement of the other system. This means that the interaction between the system and the outside world is studied as shown in Figure 4. This type of approach is already closer to real-world interactions than previous studies. The system under study has neither a perfectly rigid structure nor a perfectly flexible structure. Several conclusions can be drawn when conducting the theoretical experiment.

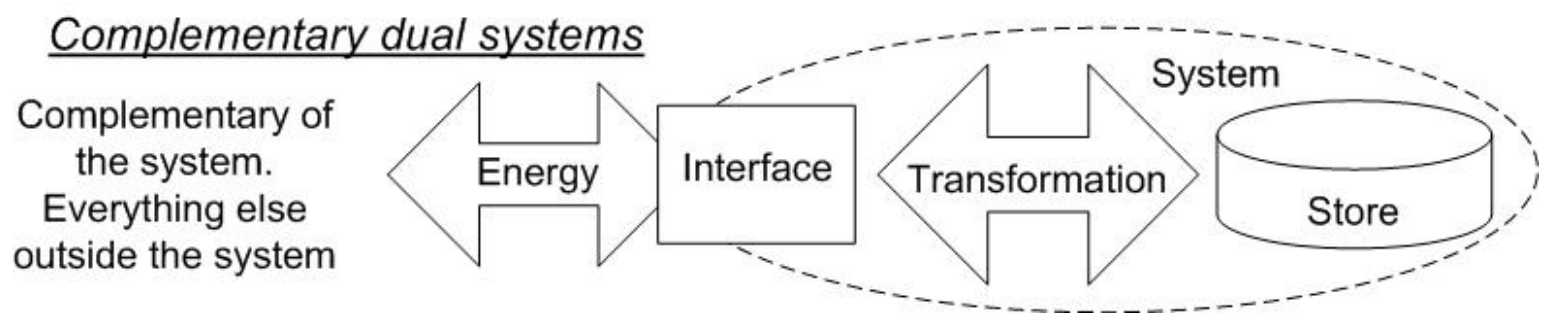

Figure 4. Model of the complementary dual systems. Based on [3].

The model of the complementary dual systems is shown in Figure 4.

The system is safe until a larger amount of energy arrives in its direction than it can store or pass. At higher energy doses, the system reacts as a rigid structure. Its structure is forced to change. The system then moves in the direction of the singularity. With a lower dose of energy, the system can store the excess. The structure of the system varies according to its own capabilities. In this case, the system moves towards balance with its environment. The general equation of the complementary dual system model is (7).

$$
0<\mathrm{E}_{\text {system }}(\text { in })=\mathrm{E}_{\text {environment }}(\text { out })<\infty .
$$

The results of the study show the basic condition for the long-term energy sustainability of a general system. The system is most secure under the conditions if it is possible to ensure the storage and transmission of excess energy for all time intervals. This means that the change of the system must also be of this nature. All this suggests exponential behavior. This involves continuous flexibility. At the same time, the energy level of the environment can be characterized by infinity at the scale of the system. Therefore, the continuous flexibility of the system and thus its continuous sustainability can be increased by increasing the energy of the system continuously and unlimitedly.

\section{Summary}

Industry 4.0 represents a new paradigm in terms of production. The smart city concept represents the same paradigm in terms of consumption, among other things. One of the most important features of this paradigm is to ensure long-term sustainability in all aspects [1-7].

In the present study, a unique test model has been developed to study the energy sustainability of systems. Using the test model, the theoretical problems of closed systems were first investigated. Subsequently, the temporal motion of rigidly structured systems was analyzed, which showed that such systems strive for singularity - they swallow up each other. Then, the study of flexible systems revealed that these systems strive for balance with their environment. Finally, a closer examination of the system showed that the basic condition for the energy sustainability of systems is that the system's own energy should increase continuously and unlimitedly. This result is consistent with the experience that the energy of long-life systems increases exponentially.

Funding: This research received no external funding. 


\section{References}

1. Bernardi, D.; Pawlikowski, E.; Newman, J. A General Energy Balance for Battery Systems. J. Electrochem. Soc. 1985, 132, 5-12. [CrossRef]

2. Kasac, J.; Stefancic, H.; Stepanic, J. Comparison of social and physical free energies on a toy model. Phys. Rev. E 2004, 1, 16117-16124. [CrossRef] [PubMed]

3. Albini, A.; Rajnai, Z. Modeling general energy balance of systems. Procedia Manuf. 2019, 32, 374-379. [CrossRef]

4. Tokody, D.; Schuszter, G.; Papp, J. Study of How to Implement an Intelligent Railway System in Hungary. In Proceedings of the 2015 IEEE 13th International Symposium on Intelligent Systems and Informatics (SISY), Subotica, Serbia, 17-19 September 2015; Szakál, A., Ed.; IEEE: New York, NY, USA, 2015.

5. Kiss, M.; Breda, G.; Muha, L. Information security aspects of Industry 4.0. Procedia Manuf. 2019, 32, 848-855. [CrossRef]

6. Tokody, D. Digitising the European industry-holonic systems approach. Procedia Manuf. 2018, 22, 1015-1022. [CrossRef]

7. Szabó, Z. The effects of globalization and cyber security on smart cities. Interdiscip. Descr. Complex Syst. 2019, 17, 503-510. [CrossRef]

8. Kovács, Z. Cloud Security in Terms of the Law Enforcement Agencies. Hadmérnök 2012, 7, 144-156.

9. Mester, G. Rankings Scientists, Journals and Countries Using h-index. Interdiscip. Descr. Complex Syst. 2016, 14, 1-9. [CrossRef]

10. Dobrilovic, D.; Odadzic, B. Virtualization Technology as a Tool for Teaching Computer Networks. Int. J. Educ. Pedagog. Sci. 2008, 13, 41-45.

11. Mester, G. Academic Ranking of World Universities 2009/2010. IPSI J. Trans. Internet Res. TIR 2011, 7, 44-47.

12. Albini, A.; Tokody, D.; Rajnai, Z. Theoretical Study of Cloud Technologies. Interdiscip. Descr. Complex Syst. 2019, 17, 511-519. [CrossRef]

13. Albini, A.; Rajnai, Z. General Architecture of Cloud. Procedia Manuf. 2018, 22, 485-490. [CrossRef]

14. Albini, A.; Mester, G.; Iantovics, B.L. Unified Aspect Search Algorithm. Interdiscip. Descr. Complex Syst. 2019, 17, 20-25. [CrossRef]

15. Mester, G. Obstacle Avoidance and Velocity Control of Mobile Robots. In Proceedings of the 6th International Symposium on Intelligent Systems and Informatics SISY 2008, Subotica, Serbia, 26-27 September 2008; Catalog Number CFP0884C-CDR. IEEE: Piscataway, NJ, USA, 2008; pp. 97-101.

16. Mester, G.; Rodic, A. Sensor-Based Intelligent Mobile Robot Navigation in Unknown Environments. Int. J. Electr. Comput. Eng. Syst. 2010, 1, 55-66.

17. Szabó, A.; Szucs, E.; Berek, T. Illustrating Training Opportunities Related to Manpower Facility Protection through the Example of Máv Co. Interdiscip. Descr. Complex Syst. 2018, 16, 320-326. [CrossRef]

18. Mester, G.; Pletl, S.; Pajor, G.; Basic, D. Adaptive Control of Rigid-Link Flexible-Joint Robots. In Proceedings of the 3rd International Workshop of Advanced Motion Control, Berkeley, CA, USA, 20-23 March 1994; pp. 593-602.

19. Mester, G.; Pletl, S.; Nemes, A.; Mester, T. Structure Optimization of Fuzzy Control Systems by Multi-Population Genetic Algorithm. In Proceedings of the 6th European Congress on Intelligent Techniques and Soft Computing, EUFIT'98, Aachen, Germany, 7-10 September 1998; Verlag Mainz: Aachen, Germany, 1998; pp. 450-456.

20. Mester, G.; Rodic, A. Simulation of Quad-rotor Flight Dynamics for the Analysis of Control, Spatial Navigation and Obstacle Avoidance. In Proceedings of the 3rd International Workshop on Advanced Computational Intelligence and Intelligent Informatics (IWACIII 2013), Shanghai, China, 18-21 October 2013; pp. 1-4.

21. Zamfirescu, C.B.; Duta, L.; Iantovics, L.B. The Cognitive Complexity in Modelling the Group Decision Process. BRAIN Broad Res. Artif. Intell. Neurosci. 2010, 1, 69-79.

22. Shatnawi, M.M. Applying Information Security Risk Management Standards Process for Automated Vehicles. Bánki Rep. 2019, 2, 70-74.

23. Albininé Budavári, E.; Rajnai, Z. The Role of Additional Information in Obtaining information. Interdiscip. Descr. Complex Syst. 2019, 17, 438-443. [CrossRef] 
24. Hell, P.M.; Varga, P.J. Drone systems for factory security and surveillance. Interdiscip. Descr. Complex Syst. 2019, 17, 458-467. [CrossRef]

25. Pető, R. Security of Smart City. Interdiscip. Descr. Complex Syst. 2019, 1, 13-19. [CrossRef]

Publisher's Note: MDPI stays neutral with regard to jurisdictional claims in published maps and institutional affiliations.

(C) 2020 by the authors. Licensee MDPI, Basel, Switzerland. This article is an open access article distributed under the terms and conditions of the Creative Commons Attribution (CC BY) license (http://creativecommons.org/licenses/by/4.0/). 